\title{
Stress in the Patella Following Autologous Chondrocyte Implantation - A Finite Element Study

\author{
Walker RW ${ }^{1}$, Cheah $\mathbf{K}^{2}$, Ingle $\mathbf{P}^{1}$ and Mootanah $\mathbf{R}^{1 *}$
}

${ }^{1}$ Medical Engineering Research Group, Department of Engineering and the Built Environment, Faculty of Science and Technology, Anglia Ruskin University, Chelmsford, Essex, CM1 1SQ, UK

${ }^{2}$ Orthopaedic Department, Ramsay Springfield Hospital, Chelmsford, Essex, CM1 7GU, UK

\begin{abstract}
Bovine patella cartilage shows signs of damage and cell death when subjected to a compressive cyclic load of 6 $\mathrm{MPa}$, which results in a shear stress of 5.6 MPa. The aim of this research was to investigate the effect of activities of daily living (descending stairs, bicycling and deep flexion) on the contact stresses in the patellofemoral compartment following an articular chondrocyte implantation. A finite element (FE) model of the patellar femoral joint was created and dynamic non-linear analyses were carried out for this purpose. A shear stress of 5.6 MPa was used as the threshold that cartilage can tolerate without resulting in damage. The FE model was verified numerically.

Our results show that, for a $70 \mathrm{~kg}$ individual at $50 \%$ recovery, (i) contact stress in the patella is $11 \%$ higher than that in the femur; (ii) shear stress in the host cartilage reaches $4.75 \mathrm{MPa}$ at $50^{\circ}$ of flexion; (iii) shear stress in the patella host cartilage is twice that in a healthy cartilage during deep flexion approaching $70^{\circ}$; (iv) maximum shear stress value was $2.75 \mathrm{MPa}$ during cycling at $60 \%$ load; (v) stress shielding still occurs through the host cartilage even when the implanted cartilage reaches $97.5 \%$ the Young's modulus of a healthy cartilage. Based on these results, (i) using an exercise bicycle is recommended for rehabilitation; (ii) deep knee flexion should be avoided; (iii) obese people with a BMI of over $42 \mathrm{~kg} / \mathrm{m}^{2}$ should not undertake vigorous weight-bearing exercises involving deep knee flexion.
\end{abstract}

Keywords: Autologous chondrocyte implantation; Patellofemoral joint; Finite element method; Knee cartilage; Shear stress; Contact stress

\section{Introduction}

Autologous Chondrocyte Implantation (ACI) is a procedure that was developed in 1987 by Brittberg and colleagues in Gothenburg (Sweden) to repair damaged cartilage. It involves harvesting chondrocytes from healthy tissue, growing the cells in tissue culture, and implanting the expanded cells into the chondral defect. Trials are in progress at the Royal National Orthopaedic Hospital in Stanmore (UK) and its co-ordinating hospitals, as well as Agnes Hunt Orthopaedic Hospital in Oswestry (UK). However, NICE approval is still awaited for ACI to be an approved NHS treatment.

Clinical outcomes of ACI have been showing mixed results over the years. ACI results show a significant improvement in the quality of life [1-3]. Studies by Richardson [4] showed that, 12 months following surgery, the implanted femoral cartilage had regenerated into a reasonable approximation of the natural cartilage. Bartlett et al. [1] and Peterson et al. [5] claim it will take the implant more than 12 months before mechanical properties approach that of the original cartilage. Noyes and Barber-Westin reviewed 11 studies, involving 613 knees that underwent ACI in the patella and reported that $8 \%-60 \%$ of the patients failed to achieve a benefit after the operation [6]. The success rates of implants on the patella are not as high [1] as the femur.

Excessive stress acting on the implant, as well as very low stress, could inhibit the formation of the dense network of type II collagen fibres, which are essential for healthy cartilage. This could lead to inferior mechanical properties of and damage to the host cartilage [7]. It is therefore critical that the contact stress in the implant is high enough to encourage the formation of the dense network of type II collagen fibres, but not too high to cause damage to the chondrocyte cells that form those fibres. This could be influenced by the location of defects and thickness of the cartilage. Clement and co-investigators [8] reported that bovine patella cartilage showed signs of damage and cell death when subjected to a compressive cyclic load of $6 \mathrm{MPa}$. This corresponds to a shear stress of $5.6 \mathrm{MPa}$ at $4 \mathrm{~mm}$ below from the surface of the cartilage (thickness of the human patellar cartilage).

In classical engineering situations, the normal cause of failure is the maximum shear stress, which occurs at a distance below the surface. This distance increases as the contact force increases [9]. In the human body, where cartilage contact occurs, the stress patterns are much more complex than in most engineering applications due to the irregular geometry of the contact surfaces and the non-homogeneous nature of the materials in the contact zone. The consequence of these factors is that the stresses at the interfaces between the different layers of materials can become magnified and direct analytical solutions of the contact stress cannot be expected to give accurate answers. Finite Element (FE) method is a well-accepted tool to predict stresses in reconstructed joints. The maximum shear stress for a joint under normal physiological conditions is likely to occur at the calcified layer between the cartilage and the bone. ACI failures have been reported in this region of the patella [5]. The aim of this research was therefore

*Corresponding author: Rajshree Mootanah, Medical Engineering Research Group, Department of Engineering and the Built Environment, Faculty of Science and Technology, Anglia Ruskin University, Chelmsford, Essex, CM1 1SQ, UK, Tel: (44) 1245 683909; E-mail: rajshree.mootanah@anglia.ac.uk

Received August 29, 2013; Accepted October 18, 2013; Published October 25 2013

Citation: Walker RW, Cheah K, Ingle P, Mootanah R (2013) Stress in the Patella Following Autologous Chondrocyte Implantation - A Finite Element Study. J Comput Sci Syst Biol 6: 305-310. doi:10.4172/jcsb.1000126

Copyright: (c) 2013 Walker RW, et al. This is an open-access article distributed under the terms of the Creative Commons Attribution License,which permits unrestricted use, distribution, and reproduction in any medium, provided the original author and source are credited. 
to identify a causal link between activities of daily living (ADL) and excessive shear stress in the region of the implanted cartilage that is likely to result in implant failure.

\section{Methods}

A three dimensional (3D) FE model of the patellofemoral knee joint was created to predict shear stress produced following common ADLs.

\section{Geometry}

A computer aided design (CAD) model of the patellofemoral compartment of the knee joint was constructed in I-Deas (I-Deas, 11.1, SDRC) based on published dimensions [10] (Figure 1). Other dimensions were taken from the life size knee model produced by Adam and Rouilly Ltd (model ME38) [11]. The implant was modelled as a single large defect on the face of the patella. The post debridement size of the defect was $35 \mathrm{~mm}$ wide by $15 \mathrm{~mm}$ high, which is considered to be a large defect that can be treated by ACI. The shape of the defect modelled is shown in bold black lines in Figure 7. The 3D CAD model was initially used to develop non-linear dynamic FE models of a healthy knee in LS-Dyna 970.

\section{Material properties}

The 3D model was partitioned in I-Deas to allow the various material properties to be allocated to the bone and healthy cartilage. LS-Dyna material formula 6 for visco-elastic material [12] was used to simulate the load/relaxation curves published by Korhonen et al. [13]. The model was then adapted to simulate a patellofemoral joint that has undergone a $35 \mathrm{~mm}$ wide and $15 \mathrm{~mm}$ high ACI by changing the material properties of the elements in the region of the ACI.

$$
\begin{aligned}
& \mathrm{G}(\mathrm{t})=\mathrm{G}_{\infty}+\left(\mathrm{G}_{0}-\mathrm{G}_{\infty}\right) \mathrm{e}^{-\beta \mathrm{t}} \\
& K=\frac{E}{3(1-2 v)} \\
& K=\frac{E}{3(1-2 v)} \\
& \text { Where: } \\
& \mathrm{E}=\text { Young's modulus } \\
& \mathrm{G}=\text { Shear modulus } \\
& \mathrm{K}=\text { Bulk modulus } \\
& v=\text { Poisson's ratio }
\end{aligned}
$$

$\beta=$ Decay constant, calculated to be -0.027 from the gradient of Korhonen's et al. [13] variation of shear modulus with time graph.

$$
\mathrm{t}=\text { Time }(\mathrm{s})
$$

The material properties, computed from the above information, were allocated to cartilage at different levels of recovery are given in Table 1. In the absence of any scientific data on the properties of human cartilage as it regenerates [5,15], we assumed that regeneration followed the logistics curve for most biological recovery processes [16].

\section{Boundary conditions}

The outer surfaces of the patella and femur were retained in 5 degrees of freedom and only allowed to move in flexion. This is because the patella tendon and the quadriceps muscle restrain the patella in the vertical direction during standing. The medial and lateral retinacula prevent patella rotation about the vertical axis. The patella ridge, together with the surrounding soft tissue, allows patella movement in only one direction, into and away from the femur. Common nodes were used between cartilage and bone to represent perfect bonding. Automatic single surface contact elements were used between the patellar and femoral cartilages to allow relative motion and prevent penetration between the two surfaces.

Figure 2 shows the patellofemoral load flexion curves of the stance phase which were used in the non-linear FE model to simulate the patients undertaking the following three typical activities of daily living:

Descending stairs with a $200 \mathrm{~mm}$ high step (the largest recommended by British Standards) [17]

Patient going into deep knee flexion [18]

Patient using an exercise bicycle, generating $157 \mathrm{~W}$ at $80 \mathrm{rpm}$ [19].

Loads corresponding to values in Figure 2 were applied normal to the outer surface of the patella for each activity at different angles of flexion. Information about time for each activity [20] was input in LS-Dyna to simulate the dynamic loading conditions. Patellofemoral forces during the swing phase of a step were not included as this would not produce significant compressive stresses in the cartilage.

Step descent was selected as it is an activity that must be undertaken by most patients during recovery. Deep flexion and cycling an exercise bicycle were modelled as they are used in physiotherapy during the recovery period. This data assumed an anatomically correct knee joint. Malaligned joints were not considered in this study.

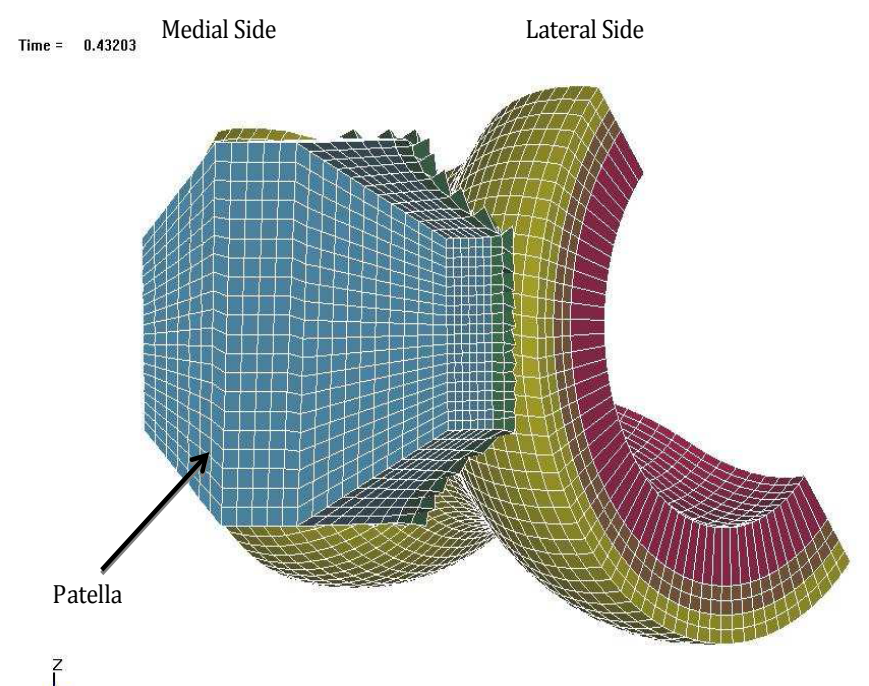

Figure 1: A three-dimensional finite element model of the patellofemoral joint at $45^{\circ}$ flexion.

\begin{tabular}{|l|c|c|c|c|}
\hline Recovery & K (MPa) & Go (MPa) & $\mathbf{G} \infty(\mathbf{M P a})$ & $\mathbf{E}(\mathbf{M P a})$ \\
\hline 25\% of recovery following stage 2 & 137.8 & 8.44 & 3.04 & 25 \\
\hline 50\% of recovery following stage 2 & 444 & 27.2 & 9.80 & 80 \\
\hline 75\% of recovery following stage 2 & 723 & 44.3 & 15.9 & 130 \\
\hline Healthy cartilage & 861 & 52.7 & 19.0 & 155 \\
\hline
\end{tabular}

Table 1: Visco-elastic material constants used for cartilage, computed from the logistics curve for most biological recovery processes [5]. $K$ is the bulk modulus $G_{0}$ is the initial shear modulus, $G_{\infty}$ is the shear modulus after a load has been applied for an infinite time, $E$ is the Young's modulus. 


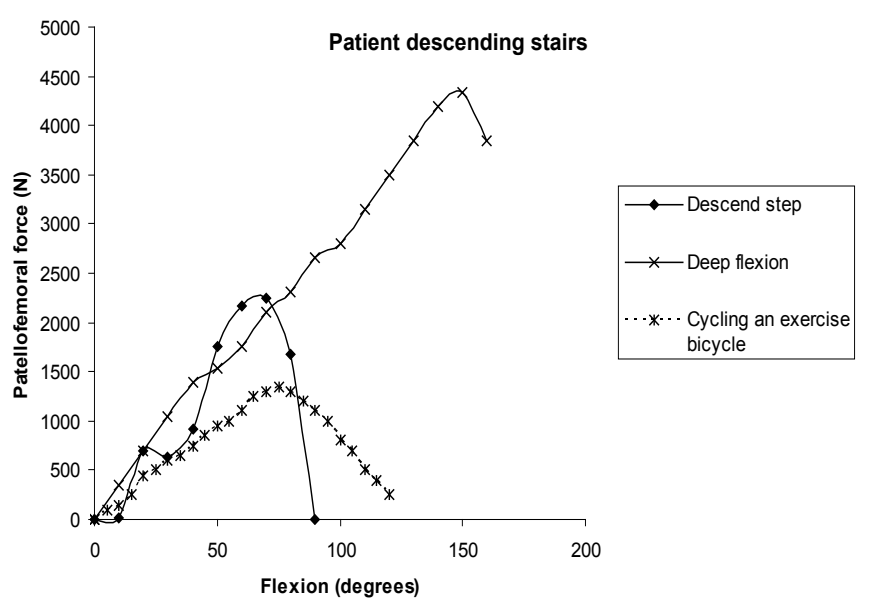

Figure 2: Patellofemoral force based on $70 \mathrm{~kg}$ healthy person during deep flexion [1] , step descent [2] and cycling [3]. The time taken to carry out the above activities was obtained from the work of Taylor and Walker [4].

\section{Element size}

The FE model of the patellofemoral compartment of the knee joint was meshed (in I-Deas, SDRC), using nominally $4 \mathrm{~mm}$ and $2 \mathrm{~mm}$ low order brick elements, throughout the model. Mesh sizes of $2 \mathrm{~mm}$ and 4 $\mathrm{mm}$ were initially allocated to give a good aspect ratio in the cartilage. Only a $3 \%$ difference in shear stress values was observed between the results from $2 \mathrm{~mm}$ and $4 \mathrm{~mm}$ elements. The number of elements for the $2 \mathrm{~mm}$ and $4 \mathrm{~mm}$ meshes were 11520 and 1640, respectively, of which 6620 and 840 were for the cartilage of $2 \mathrm{~mm}$ and $4 \mathrm{~mm}$ elements, respectively. For this reason, the analysis was carried out using $4 \mathrm{~mm}$ brick elements.

\section{Verification of the FE model}

The FE model was verified numerically and by comparing our results with experimental data from literature. To verify results of our FE model with published experimental values, we applied loading conditions used by Clements et al. [8] in their ex vivo study on six cadaveric knees and compared results [8]. When applying a load of $1300 \mathrm{~N}$ at a flexion angle of $30^{\circ}$, Clements et al. reported contact areas of $305 \pm 95 \mathrm{~mm}^{2}$ and $294 \pm 101 \mathrm{~mm}^{2}$, when using pressure sensitive film and MRI scans, respectively, and contact pressure of $5.5 \pm 2.1 \mathrm{MPa}$ when using pressure sensitive film. These findings agree with those of our FE results.

Our FE results were verified numerically, using Hertzian contact mechanics [9], based on the following parameters:

Radius of the femoral condyle: $22 \mathrm{~mm}$

Width of the patella: $45 \mathrm{~mm}$

Load applied: $1300 \mathrm{~N}$

Young's modulus of cartilage: $155 \mathrm{MPa}$,

Poisson's ratio of cartilage 0.47

Coefficient of friction: 0.01 .

The results produced were:

Contact Area $=301.5 \mathrm{~mm}^{2}$

Maximum pressure $=5.49 \mathrm{MPa}$
The results from LS-Dyna using $4 \mathrm{~mm}$ mesh were:

Contact pressure: $5.0 \mathrm{MPa}-5.5 \mathrm{MPa}$

Contact area: $290 \mathrm{~mm}^{2}$

The results from LS-Dyna using $2 \mathrm{~mm}$ mesh were:

Contact pressure: $5.5 \mathrm{MPa}$

Contact area: $305 \mathrm{~mm}^{2}$

Results of our FE model agreed closely with numerical model derived from Hertzian's contact mechanics and published ex-vivo investigations. The FE model was then used to predict contact stresses in a patellofemoral compartment following an ACI.

\section{Stress analysis}

Contact and shear stress values were investigated in the different regions of the patellar cartilage. A threshold shear stress value of 5.6 $\mathrm{MPa}$ was assigned to our FE model to represent the point at which failure in the human patella cartilage can be expected. This is based on the work of Clements et al. [8], which showed that that the cartilage could be damaged by repeated stress levels well below those expected to cause failure. Although these tests were carried out on bovine cartilage and extrapolating the results to human cartilage may be considered questionable, they are the only guide we have for failure that can be considered akin to metal fatigue. Shear stress is discussed in the rest of this paper as it contributes most to damage in classical contact mechanics [9].

\section{Results}

Results of shear stresses in the healthy and reconstructed patellofemoral compartments are shown in Figure 3. Contact stress in the patella is higher than in the femur by approximately $11 \%$ for a person of mass $70 \mathrm{~kg}$. The peak stress in the patella occurs after the peak stress in the femur and after the maximum load when descending stairs. For comparison purposes various patients' weights were also analysed and the extrapolated results predicted a critical value of shear stress of 5.6MPa occurring when a person has a BMI of $42(131 \mathrm{~kg})$.

\begin{tabular}{|l|l|l|l|l|l|}
\hline $\begin{array}{l}\text { Patient } \\
\text { mass } \mathbf{( k g )}\end{array}$ & $\begin{array}{l}\text { BMI } \\
\left(\mathbf{k g} / \mathbf{m}^{2}\right)\end{array}$ & $\begin{array}{l}\text { Patella maximum } \\
\text { averaged shear } \\
\text { stress (MPa) }\end{array}$ & Flexion & $\begin{array}{l}\text { Femur maximum } \\
\text { averaged shear } \\
\text { stress } \mathbf{( M P a )}\end{array}$ & $\begin{array}{l}\text { Flexion } \\
\text { (degrees) }\end{array}$ \\
\hline 50 & 16 & 1.76 & 67.5 & 1.56 & 67.5 \\
\hline 70 & 23 & 2.05 & 67.5 & 1.86 & 67.5 \\
\hline 90 & 29 & 2.36 & 63 & 2.20 & 72 \\
\hline 110 & 36 & 3.71 & 76.5 & 2.76 & 81 \\
\hline
\end{tabular}

Table 2: Maximum shear stress in a healthy knee, cartilage modelled as viscoelastic material for a $200 \mathrm{~mm}$ step descent.

\begin{tabular}{|l|c|}
\hline Recovery & Pedal force (N) \\
\hline Shortly after the operation & 20 \\
\hline $25 \%$ recovery in cartilage & 50 \\
\hline $50 \%$ recovery in cartilage & 50 \\
\hline $75 \%$ recovery in cartilage & 50 \\
\hline
\end{tabular}

Table 3: Recommended exercise bicycle pedal reaction force, based on patient results during cycling at $180 \mathrm{rpm}$.

Figure 3 shows the shear stress in the host cartilage and the implant in the simulated ACI patient descending stairs and contrasts these with the stresses found in a healthy knee. The shear stress was determined at various stages of recovery; however, $50 \%$ recovery is presented here as it is at this point when the implant mechanical properties show a 


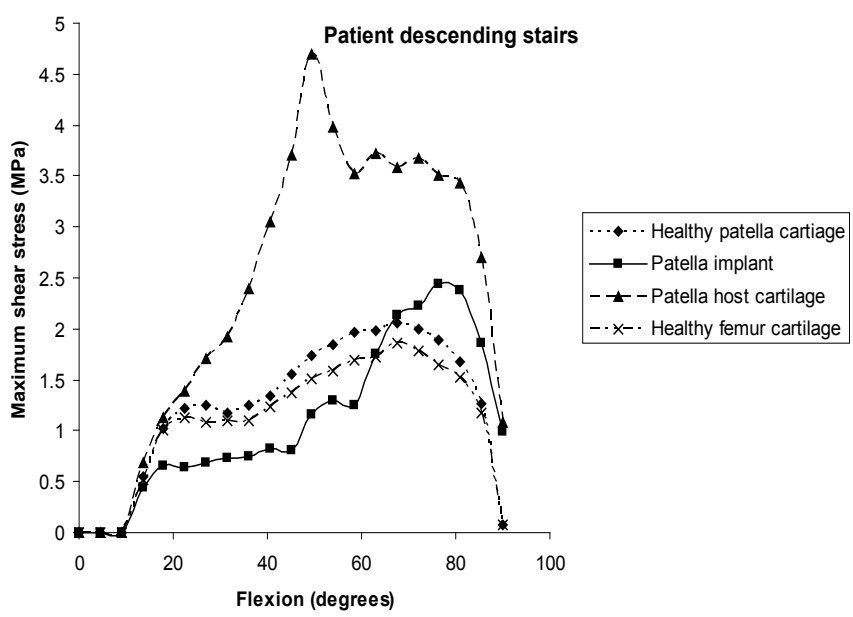

Figure 3: Element maximum shear stress in the patella host and implant cartilage at $50 \%$ recovery, $4 \mathrm{~mm}$ mesh while descending a $200 \mathrm{~mm}$ step.

significant improvement. Shear stress reaches a peak of $2.5 \mathrm{MPa}$ in the patella cartilage implant at $80^{\circ}$ of flexion and $4.75 \mathrm{MPa}$ in the host cartilage at $50^{\circ}$ of flexion. The remaining pressure curves for the ACI at $50 \%$ recovery are lower than pressure values for healthy cartilage, which are to be expected when the Young's modulus of the cartilage has not yet developed to its full value.

Figure 4 shows the shear stress in the patella host cartilage and the implant at $50 \%$ recovery in the cartilage properties and going into deep flexion. The solution failed at $75^{\circ}$ flexion due to 'negative volume elements'; however it does indicate that the stress is approximately twice the stress expected in a healthy knee.

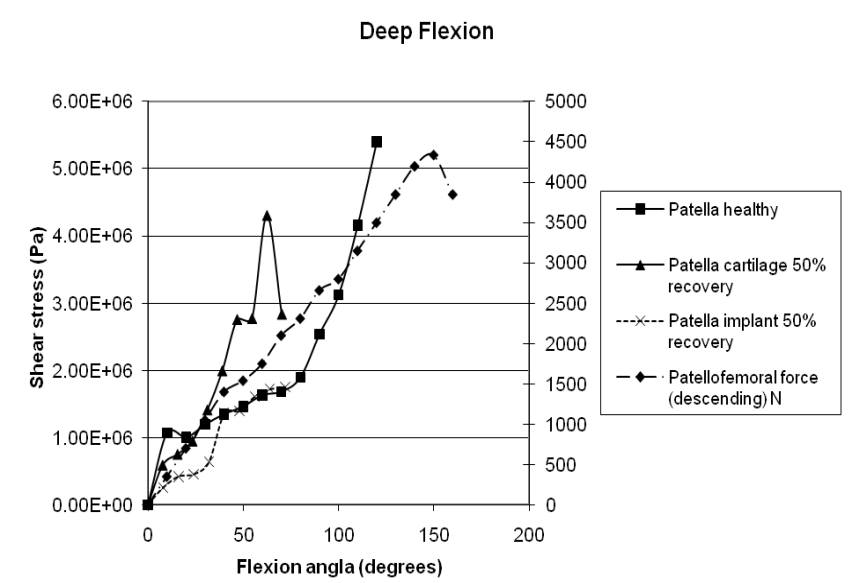

Figure 4: Element maximum shear stress in the patella host cartilage and the implant at $50 \%$ recovery going into deep flexion. Y-axis on the right shows Force in $\mathrm{N}$.

Figure 5 shows that the shear stresses in the patella host cartilage and the implant do not exceed $2.75 \mathrm{MPa}$ while cycling an exercise bicycle. The maximum pedal force recommended from our modelling is $100 \mathrm{~N}$ when recovery is expected to be complete.

Figure 6 shows that, even when the implant has a Young's modulus of $97.5 \%$ of the host cartilage, there is still a difference in the stress distribution between the host cartilage and the implant. Figure 7 and

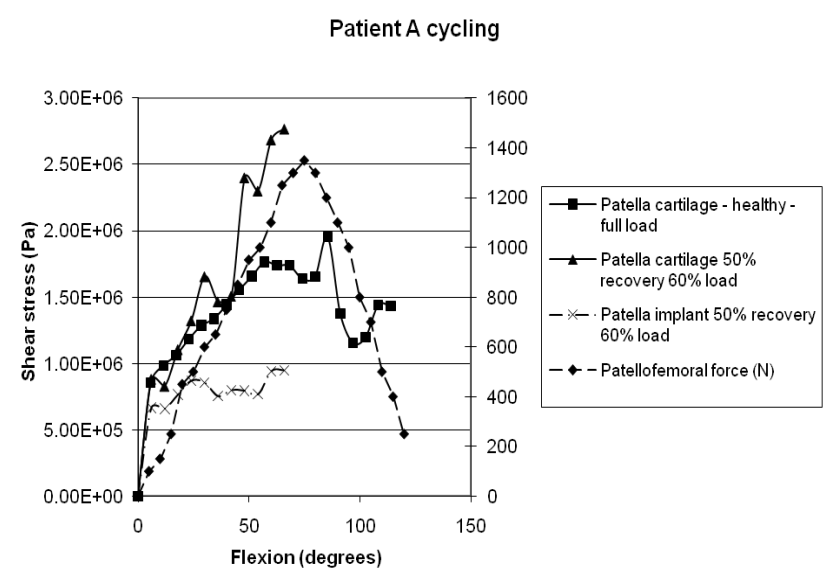

Figure 5: Element maximum shear stress in the patella host cartilage and implant cartilage at $50 \%$ recovery applying a force of $60 \mathrm{~N}$ during cycling. $\mathrm{Y}$-axis on the right shows Force in $\mathrm{N}$.

8 show FE analyses plots of contact pressure contours in the healthy and reconstructed patella cartilage at $54^{\circ}$ of flexion. The difference in the contour patterns between the two diagrams show that, even when the implanted cartilage is $97.5 \%$ of the Young's modulus of healthy cartilage, there is a critical difference in the stress at the host/implant interface.

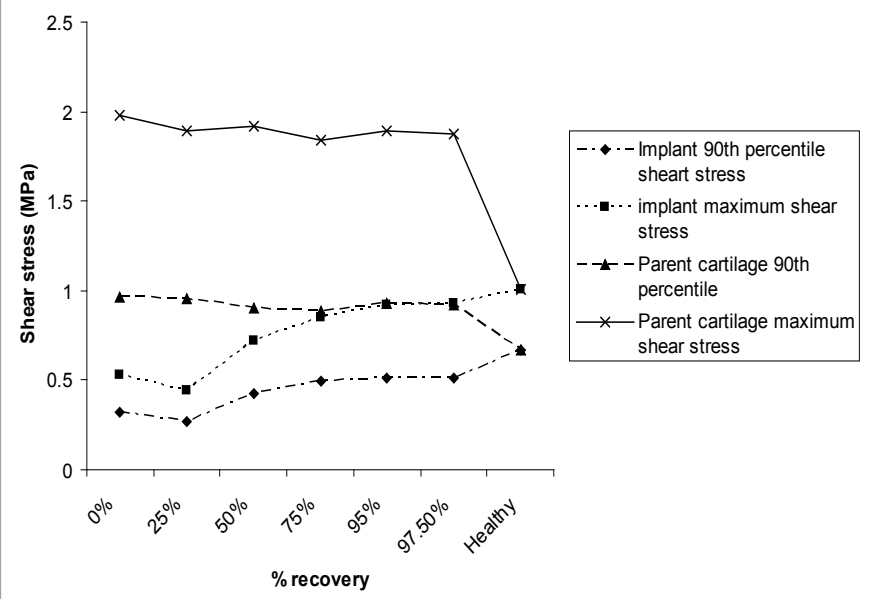

Figure 6: Convergence of the stresses in the cartilage as recovery progresses, $30^{\circ}$ flexion, $1300 \mathrm{~N}$ load

\section{Discussion}

Several finite element models of the patellar femoral compartment of the knee joint have been created to investigate the link between patellar femoral stress and knee pain [21], relationships between shape and function [22], implant design and outcome [23-27], and the influence of femoral internal and external rotation on patellar femoral cartilages [28]. To our knowledge, no study has investigated the effect of knee joint contact stresses following an ACI. Our FE model were verified numerically, using Hertzian contact mechanics and results of ex-vivo studies from literature [8] and was used to predict patellar femoral joint stress during stair descent, deep flexion and cycling following an ACI. 


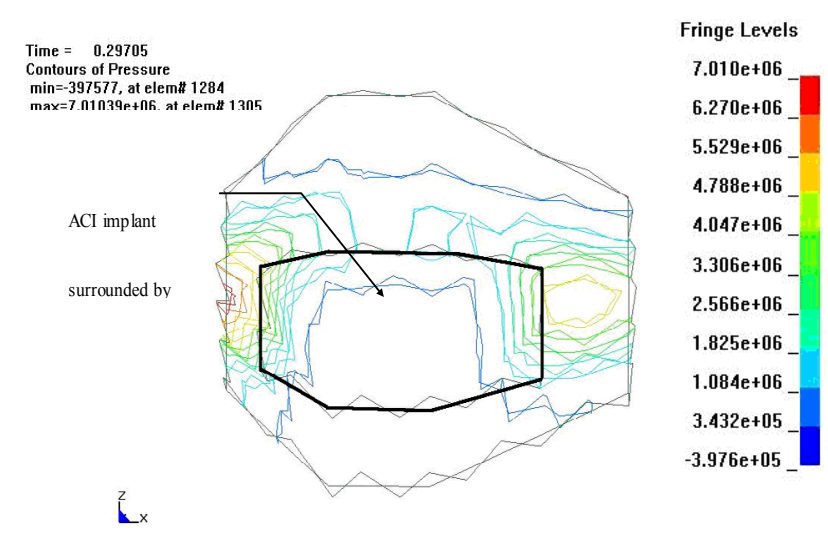

Figure 7: FEA plot of pressure contours $(\mathrm{Pa})$ in the patella cartilage of patient $\mathrm{A}$ at $97.5 \%$ recovery of implant properties, $54^{\circ}$ flexion and contact force of $2150 \mathrm{~N}$.

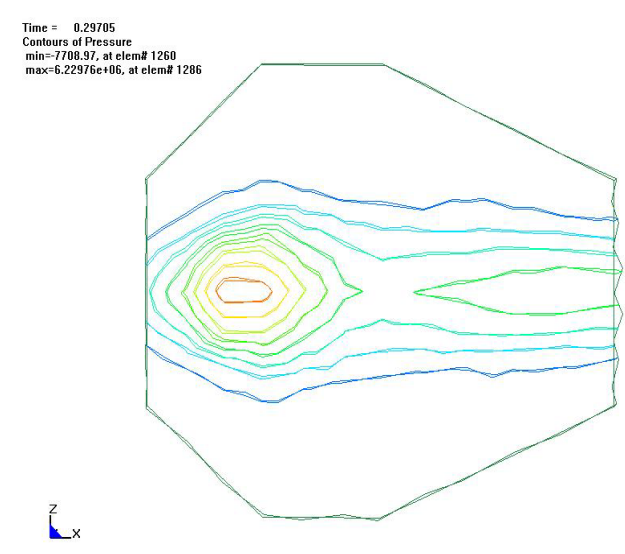

Fringe Levels

$6.230 \mathrm{e}+06$

$5.606 \mathrm{e}+06$

$4.982 \mathrm{e}+06$

$4.359 \mathrm{e}+06$

$3.735 \mathrm{e}+06$

$3.111 \mathrm{e}+06$

$2.487 \mathrm{e}+06$

$1.864 \mathrm{e}+06$

$1.240 \mathrm{e}+06$

$6.160 \mathrm{e}+05$

$-7.709 \mathrm{e}+03$

Figure 8: Pressure contours $(\mathrm{Pa})$ in healthy patella cartilage, $54^{\circ}$ flexion and a contact force of $2150 \mathrm{~N}$

Our results show that contact stress in the patellar femoral joint increases exponentially with patient weight. FE stress results for a person with a healthy knee and a body mass index greater than 42 $\mathrm{kg} / \mathrm{m}^{2}$ indicate that permanent damage to the cartilage can occur if repeated exercise is carried out, especially where the patient's body mass is an inherent part of the exercise. This agrees with the results from large scale studies on the correlation between body mass index and osteoarthritis $[27,29,30]$. Ideally, clinically obese people should exercise where the body mass has little impact on the knee joint, for example, by using an exercise bicycle.

The results for ACI with a Young's Modulus of $97.5 \%$ of that of healthy cartilage show that stress shielding still occurs through the healthy cartilage (Figures 6-8). The decrease in stress in the implant could restrict its normal growth pattern, which reacts positively to an applied stress [31]. The significance of this is that regeneration of the implanted collagen fibre will be inhibited by the lack of stress and the surrounding normal cartilage may be damaged by excessive stress. Our study implies that, even at $97.5 \%$ recovery, damage to the host cartilage surrounding the implant may still result, especiallyfor activities that demand high flexion and high patellofemoral force.
This study shows that stress in the patella is higher than that in the femur. This could be due to fact that patellar cartilage is thicker femoral cartilage. All the above factors add to the difficulty in making unequivocal recommendations based on the analysis of the contact stress. The study does, however, explain why the reported failures at the interface of the cartilage and the bone of the patella and also the implant and the host cartilage occur [5].

Peak shear stress of 4.5 $\mathrm{MPa}$ and 4.75 $\mathrm{MPa}$ in the host patella cartilage at $50^{\circ}$ flexion during deep flexion (Figure 3 ) and stair descent (Figure 4), respectively, suggests that deep flexion beyond $50^{\circ}$ cannot be recommended as the shear stress could damage the implant and the surrounding host cartilage. Although these stresses are lower than the critical value of 5.6 MPa [8], a more arduous activity or higher patient weight could result in damage to the host cartilage and implant. Shear stress at the interface of the implant and the host cartilage is above that expected at larger degrees of flexion because pressure increases exponentially with flexion, as shown in Figure 7 and 8.

The lower peak shear stress of $2.75 \mathrm{MPa}$ in the patella host cartilage at $70^{\circ}$ flexion during cycling at an applied force of $60 \mathrm{~N}$ demonstrates the benefit of this form of exercise for a patient recovering from ACI. The added advantage is that patellofemoral stress is not affected by cycling and physiotherapists can set the pedal force. However, the patient must be discouraged from using the exercise bicycle to maintain a high level of fitness during recovery as exercise that is too vigorous may still damage the knee.

Our results show that, during the recovery period, activities that result in high patellofemoral forces must be strongly discouraged. However, some stress in the implant is necessary to ensure the formation of the dense collagen fibres essential for healthy cartilage. It is therefore imperative that a good balance of exercise regime is set and adhered to by the patient, otherwise the implant could fail.

Whilst results of this study contributes to useful information that can help with making informed decision regarding rehabilitation plans for patients following an ACI, the following limitations need to be considered:

The FE patellofemoral model used simulated an anatomically correct, well-aligned joint. Hence, these results do not reflect those produced from a malaligned knee joint, which is often associated with osteoarthritis [21,32-35]. Further study on stress in the patellofemoral compartment of a malaligned knee with ACI is warranted.

A threshold shear stress value of 5.6 MPa was used to represent the maximum stress that human cartilage can withstand without failure. This value is based on published data of ex vivo investigations carried out on bovine specimens, the closest data available for fatigue failure of cartilage [8]. Hertzian contact mechanics was used to validate our FE model, although this theory is recommended for small deformations. The authors carried out non-linear dynamic FE analysis on the knee joint to ensure that a complete picture of the stress cycle is determined. This shows the maximum stress does not always coincide with the maximum force, due to complex material properties and changing geometry.

This study demonstrates a practical method to model defects in the body or recovery from an operation by modifying the material properties of the relevant elements accordingly. However, there is a dichotomy in the recommendations. The patient needs to exercise to regenerate the collagen fibres with the correct alignment in the implant; however, too much exercise could damage the surrounding 
untreated cartilage. In addition, stress shielding of the implant by the surrounding host cartilage could prevent the collagens forming in a physiological manner.

To conclude, this study shows a systematic and detailed analysis of ACI that closely reflects activities of daily living and brings further understanding to some likely failure mechanisms. Our findings that patellofemoral knee joint stress can reach critical levels in deep flexion implies that such movement should not be recommended, especially shortly after implantation when the implant still has inferior material properties. Obese people with a BMI of over 42 should not undertake vigorous exercises that involve a high degree of knee flexion with the body mass acting on the knee, for example step aerobics. Excessive loads acting on the patellofemoral joint could cause irrevocable damage to the cartilage. Results of this study could be used during rehabilitation to help reduce the ACI failure rate.

\section{Acknowledgement}

This study was partly supported by Capio Research Foundation.

\section{References}

1. Bartlett W, Skinner JA, Gooding CR, Carrington RW, Flanagan AM, et al. (2005) Autologous chondrocyte implantation versus matrix-induced autologous chondrocyte implantation for osteochondral defects of the knee: a prospective, randomised study. J Bone Joint Surg Br 87: 640-645.

2. Vanlauwe JJ, Claes T, Van Assche D, Bellemans J, Luyten FP (2012) Characterized chondrocyte implantation in the patellofemoral joint: an up to 4-year follow-up of a prospective cohort of 38 patients. Am J Sports Med 40: 1799-1807.

3. Trinh TQ, Harris JD, Siston RA, Flanigan DC (2013) Improved outcomes with combined autologous chondrocyte implantation and patellofemoral osteotomy versus isolated autologous chondrocyte implantation. Arthroscopy 29: 566-574.

4. Richardson JB, Caterson B, Evans EH, Ashton BA, Roberts S (1999) Repair of human articular cartilage after implantation of autologous chondrocytes. J Bone Joint Surg Br 81: 1064-1068.

5. Peterson L, Minas T, Brittberg M, Nilsson A, Sjogren-Jansson E, et al. (2000) Two- to 9-year outcome after autologous chondrocyte transplantation of the knee. Clin Orthop Relat Res 212-234.

6. Noyes FR, Barber-Westin SD (2013) Advanced patellofemoral cartilage lesions in patients younger than 50 years of age: is there an ideal operative option? Arthroscopy 29: 1423-1436

7. Eckstein F, Lemberger B, Gratzke C, Hudelmaier M, Glaser C, et al. (2005) In vivo cartilage deformation after different types of activity and its dependence on physical training status. Ann Rheum Dis 64: 291-295.

8. Clements KM, Bee ZC, Crossingham GV, Adams MA, Sharif M (2001) How severe must repetitive loading be to kill chondrocytes in articular cartilage? Osteoarthritis Cartilage 9: 499-507.

9. Johnson KL (2001) In: Anonymous Contact mechanics. Cambridge: University Press.

10. Nuno N, Ahmed AM (2001) Sagittal profile of the femoral condyles and its application to femorotibial contact analysis. J Biomech Eng 123: 18-26.

11. Adam R, Rouilly (2010) Simulators, Anatomical Models And Charts For Clinical Skills and Training. 2010.

12. Hallquist JO (2006) In: Anonymous LS-Dyna Theory Manual. Livermore, CA: Livermore Software Technology Corporation.

13. Korhonen RK, Laasanen MS, Toyras J, Rieppo J, Hirvonen J, et al. (2002) Comparison of the equilibrium response of articular cartilage in unconfined compression, confined compression and indentation. J Biomech 35: 903-909.

14. Young WC, Richard B, Ali Sadegh (2011)Roark's Formulas for Stress and Strain, 8th Edition London: McGraw-Hill.

15. Gratz KR, Wong VW, Chen AC, Fortier LA, Nixon AJ, et al. (2006) Biomechanical assessment of tissue retrieved after in vivo cartilage defect repair: tensile modulus of repair tissue and integration with host cartilage. $J$ Biomech 39: 138-146.
16. Lemon G, King JR, Byrne HM, Jensen OE, Shakesheff KM (2006) Mathematical modelling of engineered tissue growth using a multiphase porous flow mixture theory. J Math Biol 52: 571-594.

17. Brechter JH, Powers CM (2002) Patellofemoral joint stress during stair ascent and descent in persons with and without patellofemoral pain. Gait Posture16: 115-123.

18. Nagura T, Dyrby CO, Alexander EJ, Andriacchi TP (2002) Mechanical loads at the knee joint during deep flexion. J Orthop Res 20: 881-886.

19. Bressel $E$ (2001) The influence of ergometer pedaling direction on peak patellofemoral joint forces. Clin Biomech (Bristol, Avon) 16: 431-437.

20. Taylor SJ, Walker PS (2001) Forces and moments telemetered from two distal femoral replacements during various activities. J Biomech 34: 839-848.

21. Kalichman L, Zhu Y, Zhang Y, Niu J, Gale D, et al. (2007) The association between patella alignment and knee pain and function: an MRI study in persons with symptomatic knee osteoarthritis. Osteoarthritis Cartilage 15: 1235-1240.

22. Fitzpatrick CK, Baldwin MA, Laz PJ, Fitzpatrick DP, Lerner AL, et al. (2011) Development of a statistical shape model of the patellofemoral joint for investigating relationships between shape and function. J Biomech 44: 24462452.

23. D'Lima DD, Chen PC, Kester MA, Colwell CW Jr (2003) Impact of patellofemora design on patellofemoral forces and polyethylene stresses. J Bone Joint Surg Am 4: 85-93.

24. Dargahi J, Najarian S, Amiri S (2003) Optimization of the geometry of total knee implant in the sagittal plane using FEA. Biomed Mater Eng 13: 439-449.

25. Heegaard JH, Leyvraz PF, Hovey CB (2001) A computer model to simulate patellar biomechanics following total knee replacement: the effects of femoral component alignment. Clin Biomech (Bristol, Avon) 16: 415-423.

26. Fitzpatrick CK, Baldwin MA, Rullkoetter PJ, Laz PJ (2011) Combined probabilistic and principal component analysis approach for multivariate sensitivity evaluation and application to implanted patellofemoral mechanics. J Biomech 44: 13-21.

27. Elbaz A, Debbi EM, Segal G, Haim A, Halperin N, et al. (2011) Sex and Body Mass Index Correlate With Western Ontario and McMaster Universities Osteoarthritis Index and Quality of Life Scores in Knee Osteoarthritis. Arch Phys Med Rehabil 92: 1618-1623.

28. Besier TF, Gold GE, Delp SL, Fredericson M, Beaupre GS (2008) The influence of femoral internal and external rotation on cartilage stresses within the patellofemoral joint. J Orthop Res 26: 1627-1635.

29. Teichtahl AJ, Wluka AE, Wang Y, Hanna F, English DR, et al. (2009) Obesity and adiposity are associated with the rate of patella cartilage volume loss over 2 years in adults without knee osteoarthritis. Ann Rheum Dis 68: 909-913.

30. McAlindon T, Zhang Y, Hannan M, Naimark A, Weissman B, et al. (1996) Are risk factors for patellofemoral and tibiofemoral knee osteoarthritis different? J Rheumatol 23: 332-337.

31. Ballyns JJ, Bonassar LJ (2011) Dynamic compressive loading of image-guided tissue engineered meniscal constructs. J Biomech 44: 509-516.

32. Elahi S, Cahue S, Felson DT, Engelman L, Sharma L (2000) The association between varus-valgus alignment and patellofemoral osteoarthritis. Arthritis Rheum 43: 1874-1880.

33. Cahue S, Dunlop D, Hayes K, Song J, Torres L, et al. (2004) Varus-valgus alignment in the progression of patellofemoral osteoarthritis. Arthritis Rheum 50: $2184-2190$.

34. von Eisenhart-Rothe $\mathrm{R}$, Graichen $\mathrm{H}$, Hudelmaier M, Vogl $\mathrm{T}$, Sharma $\mathrm{L}$, et al. (2006) Femorotibial and patellar cartilage loss in patients prior to total knee arthroplasty, heterogeneity, and correlation with alignment of the knee. Ann Rheum Dis 65: 69-73.

35. Hunter DJ, Zhang YQ, Niu JB, Felson DT, Kwoh K, et al. (2007) Patella malalignment, pain and patellofemoral progression: the Health ABC Study. Osteoarthritis Cartilage 15: 1120-1127. 